\title{
A Study of the Influence of Inclusive Leadership on Employee Voice Behaviors: the Mediating Effect of LMX
}

\author{
Hui Li* \\ Business School \\ Hohai University \\ Nanjing, Jiangsu, China \\ lhui@hhu.edu.cn
}

\author{
Yong Hang \\ College of Economies and Management \\ Jiang Su maritime institute \\ Nanjing, Jiangsu, China \\ honeydog135@126.com
}

\begin{abstract}
This study applies social exchange theory to measure the influence of inclusive leadership on employee voice behaviors and the mediating effect of leader-member exchange (LMX) with 174 samples from a recent questionnaire survey in China. The results confirmed the significant positive influence of the inclusive leadership (openness, availability, accessibility) on employee voice behaviors. And the research proved that LMX had a decisive mediating effect on the effectiveness of incisive leadership to influence employee voice behaviors. As far as availability and accessibility are concerned, LMX's mediating effect is also decisive. The mediating effect of LMX is partial when openness is concerned.
\end{abstract}

Keywords-Inclusive leadership; Leader-member exchange; Employee voice behavior

\section{INTRODUCTION}

Employee voice behavior is an extra-role behavior of employees, who, besides fulfilling their routine assignments, offer constructive ideas or views that primarily aim at helping the organization achieve sustainable development and get some advantages in the fierce competition [1]. However, it has been recognized that in most cases, Chinese employees tend to be reticent about the problems they noticed in the business process due to their special cultural background.. This silence, however well meant, lowers both decision quality and innovation performance of the organization [2], and on the other hand, brings tension or slack and other negative emotions among the employees [3]. In recent years, researchers have focused their attention on employee voice behaviors. How to tap the latent human resources within an organization, fully inspire the enthusiasm of employees, and boost their initiative has become a major topic in organization management researches. It is almost universally agreed that inclusive leadership has a considerable impact on employees' attitudes and behaviors [4]. Based on the social exchange theory, this research, using LMX as the mediating variable, has made an in-depth analysis of the mediating effect of leader-member exchange(LMX) between inclusive leadership and employee voice behaviors and hopefully may help enterprise leaders to improve their management capabilities, and provide some guidance as how to motivate the employees to speak up in a constructive way .

\section{TheORETICAL DEVELOPMENT AND HyPOTHESES}

\section{A. Inclusive leadership and employee voice behavior}

The contents of employees' voice behaviors mainly include sharing their experience with their leaders as well as their solutions to a problem. Leaders are both the target of employees' suggestions, and the ultimate authority who will decide whether to adopt employees' suggestions or not. Therefore leaders have a significant influence on employee voice behaviors [5]. Lu Yang et al. have studied how the style of leadership influences employee voice behaviors from the perspective of the grounded theory, and concluded that employee voice behaviors are influenced in one way or another by the following factors: How open can a leader be? Would he encourage employees to participate in decision making process? Is he a people person? What is the overall atmosphere within the organization? [6].

The first dimension of inclusive leadership is openness, which means leaders ought to be open and capable of encouraging their employees both to actively participate in organization decision-making and to think innovatively, thus greatly stimulating employee voice behaviors [7]. The second dimension of inclusive leadership is availability, which means leaders should make themselves available when employees need their help to solve problems, thereby promoting employee voice behaviors. On the other hand, as employees can expect help or encouragements from their leaders when reporting a new problem, their enthusiasm in their job as well as in voice behaviors would be greatly motivated, which, in turn, could accelerate the cycle of recognizing and solving problems, and thus boost performance. The third dimension of inclusive leadership is accessibility, which means leaders should actively interact with their employees and get along well with them, have an open and more tolerant attitude towards them, respect and support their subordinates, and thus create a tolerant, open and equal leader-member relationship [8].Such a relationship can help employees to be aware of their leaders' support , which will be translated into a sense of safety among employees that would make them more emotionally attached to the leaders and could even lower down their defense. They 
will become more frank and honest than ever with their leaders In this way, adequate communication between leaders and employees is achieved. To sum up, the following hypotheses are proposed:

Hypothesis 1: Inclusive leadership is positively related to employee voice behaviors.

Hypothesis 1a: Openness is positively related to employee voice behaviors.

Hypothesis 1b: Availability is positively related to employee voice behaviors.

Hypothesis 1c: Accessibility is positively related to employee voice behaviors.

\section{B. Mediating effect of Leader-member exchange (LMX)}

According to the social exchange theory, high quality LMX relationship generates a sense of responsibility among employees who, after recognizing the mutual benefits between themselves and leaders, are more willing to pay back the favors they believe they get from the leaders[9].Some scholars pointed out that when employees have close ties with leaders, they will actively contribute to the organization and group goals, thus producing more behaviors conducive to organization development. On the basis of full understanding of the organization environment, employees will put forward innovative suggestions ideas as how to improve the efficiency of organization work, and boldly point out the problems concerning the operation of the organization [10].Therefore, the following hypotheses are proposed:

Hypothesis 2: LMX plays a mediating effect between inclusive leadership and employee voice behaviors

Hypothesis 2a: LMX plays a mediating effect between openness and employee voice behaviors

Hypothesis 2b: LMX plays a mediating effect between availability and employee voice behaviors

Hypothesis 2c: LMX plays a mediating effect between accessibility and employee voice behaviors

\section{METHODS}

\section{A. Sample and procedure}

A total of 224 questionnaires have been distributed, and 174 are valid, with an effective rate of $77.68 \%$. Among the respondents, $47.13 \%$ are male and $52.87 \%$ are female. The majority age group is between 26 and 35, accounting for $63.22 \%$. As to their educational background, $50.58 \%$ of the respondents have Bachelor's degrees and 34.48\% have Master's degree or higher, with only $14.94 \%$ having no degree at all, which indicates a relatively high education background among the respondents in this survey. As to their working experience, $32.18 \%$ of the respondents have worked less than 1 year, $44.25 \%$ have worked for 1 to 3 years, and only $14.37 \%$ have worked for five years or more. As to the types of enterprises they currently work in, $37.36 \%$ of the respondents come from state-owned enterprises, $33.33 \%$ from private enterprises and $29.31 \%$ from other types of enterprises.

\section{B. Measures}

Inclusive leadership ( $\alpha=0.89)$ was measured with Carmeli et al. (2010). The scale consisted of 9 questions respectively measuring three dimensions of inclusive leadership: openness $(\alpha=0.79)$, availability $(\alpha=0.80)$, and accessibility $(\alpha=0.77)$. Each dimension consisted of 3 questions describing leaders' behaviors. Employee voice behavior $(\alpha=0.88)$ was measured with Liang and Farh (2008) under the cultural context of China. The scale consisted of 10 questions respectively measuring two dimensions of employee voice behaviors: promotive employee voice behavior and suppressing employee voice behavior. Each dimension consisted of 5 questions. The Likert-type Five Point Scale (1=strongly disagree; 5=strongly agree) was adopted. LMX $(\alpha=0.81)$ was measured with Scandura \& Graen (1984). As the most commonly used scale for LMX measurement, the scale consisted of 7 questions. The Likert-type Five Point Scale (1=strongly disagree; $5=$ strongly agree) was adopted.

The control variables used in this study are gender, age, working years, enterprise nature and Position level.

\section{Results}

This study proposed that inclusive leadership (hypothesis 1), openness (hypothesis 1a), availability (hypothesis 1b) and accessibility (Hypothesis 1c) are related to the employee voice behavior. Our ordinary least squares regression analysis found that inclusive leadership $(\beta=0.35, p<0.001$ in model 2 of Table 1$)$, openness $(\beta=0.40, p<0.001$ in model 3 of Table 1$)$, availability $(\beta=0.24, p<0.01$ in model 4 of Table 1$)$ and accessibility $(\beta=0.27, p<0.001$ in model 5 of Table 1$)$ are positively related to the employee voice behavior. These results support hypotheses $1,1 \mathrm{a}, 1 \mathrm{~b}$ and $1 \mathrm{c}$.

A multiple linear regression analysis was employed to test the mediating effect of LMX between inclusive leadership (hypothesis 2), openness (hypothesis 2a), availability (hypothesis 2b), accessibility (hypothesis 2c) and employee voice behavior, respectively.

As demonstrated in model 6 of Table 1, the regression coefficient between inclusive leadership and employee voice behavior reduced from 0.35 to 0.15 , and the regression coefficient was not significant, showing that the influence of inclusive leadership on employee voice behavior was not significant and the regression coefficient was significantly reduced after adding LMX as a mediation. It showed that LMX played a complete mediating effect between inclusive leadership and employee voice behavior, verifying Hypothesis 2.

As demonstrated in model 7 of Table 1, the regression coefficient between openness and employee voice behavior reduced from 0.40 to 0.23 , showing that the regression coefficient was significantly reduced after adding LMX as an mediation, but still significant. It showed that LMX played a partly mediating effect between openness and employee voice behavior, verifying Hypothesis 2a.

As demonstrated in model 8 of Table 1, the regression coefficient between availability and employee voice behavior reduced from 0.24 to 0.02 , showing that the influence of availability on employee voice behavior was not significant 
and the regression coefficient was significantly reduced after adding LMX as a mediation. It showed that LMX played a completely mediating effect between availability and employee voice behavior, verifying Hypothesis $2 b$.

As demonstrated in model 9 of Table 1, the regression coefficient between accessibility and employee voice behavior reduced from 0.27 to 0.09 , showing that the influence of accessibility on employee voice behavior was not significant and the regression coefficient was significantly reduced after adding LMX as a mediation. It showed that LMX played a completely mediating effect between accessibility and employee voice behavior, verifying Hypothesis 2c.

TABLE I. RESULTS OF REGRESSION ANALYSIS

\begin{tabular}{|c|c|c|c|c|c|c|c|c|c|}
\hline \multirow{2}{*}{ Variables } & \multicolumn{9}{|c|}{ Employee voice behavior } \\
\hline & Model 1 & Model 2 & Model 3 & Model 4 & Model 5 & Model 6 & Model 7 & Model 8 & Model 9 \\
\hline Gender & -0.02 & -0.07 & -0.05 & -0.05 & -0.06 & -0.04 & -0.04 & -0.03 & -0.04 \\
\hline Age & 0.09 & 0.05 & 0.06 & 0.07 & 0.06 & 0.05 & 0.05 & 0.05 & 0.05 \\
\hline Education level & -0.07 & -0.07 & -0.08 & -0.08 & -0.05 & -0.05 & -0.06 & -0.05 & -0.04 \\
\hline Working years & -0.24 & -0.19 & -0.22 & -0.19 & -0.20 & -0.11 & -0.14 & -0.11 & -0.11 \\
\hline $\begin{array}{l}\text { Working years in } \\
\text { current enterprise }\end{array}$ & 0.05 & 0.07 & 0.11 & 0.05 & 0.05 & 0.02 & 0.05 & 0.00 & 0.00 \\
\hline Enterprise nature & 0.05 & 0.02 & 0.02 & 0.04 & 0.02 & 0.02 & 0.01 & 0.02 & 0.01 \\
\hline Position level & $0.31^{* *}$ & $0.23^{* *}$ & $0.21 *$ & $0.26 * *$ & $0.28 * *$ & $0.22 * *$ & $0.20 *$ & $0.23^{* *}$ & $0.23^{* *}$ \\
\hline Inclusive leadership & & $0.35 * * *$ & & & & 0.15 & & & \\
\hline Openness & & & $0.40 * * *$ & & & & $0.23 * *$ & & \\
\hline Availability & & & & $0.24^{* *}$ & & & & 0.02 & \\
\hline Accessibility & & & & & $0.27 * * *$ & & & & 0.09 \\
\hline LMX & & & & & & $0.34^{* * *}$ & $0.30 * * *$ & $0.42 * * *$ & $0.39 * * *$ \\
\hline F value & $2.79 * *$ & $5.78^{* * *}$ & $6.97 * * *$ & $3.94 * * *$ & $4.30 * * *$ & $7.52^{* * *}$ & $8.31^{* * *}$ & $7.05^{* * *}$ & $7.31^{* * *}$ \\
\hline $\mathrm{R}^{2}$ & 0.11 & 0.22 & 0.25 & 0.16 & 0.17 & 0.29 & 0.31 & 0.28 & 0.29 \\
\hline $\operatorname{adj}^{2}$ & 0.07 & 0.18 & 0.22 & 0.12 & 0.13 & 0.25 & 0.28 & 0.24 & 0.25 \\
\hline$\Delta \mathrm{R}^{2}$ & & 0.11 & 0.15 & 0.05 & 0.07 & 0.07 & 0.06 & 0.12 & 0.11 \\
\hline
\end{tabular}

\section{CONCLUSION}

This study has demonstrated that the inclusive leadership has a significant positive influence on employee voice behaviors. The inclusive leadership encourages employees to participate in organization decision-making, tolerates employees' mistakes, and pays attention to employees' needs, listens to employees' voices, thus building an open organization atmosphere, in which employees are given a high degree of freedom through two-way communications, and encouraged to report discuss and solve problems.

LMX plays a completely mediating effect between inclusive leadership and employee voice behavior. The inclusive leadership focuses on building a harmonious working relationship with employees, and allows employees to perceive that they are regarded as "insiders" through a series of inclusive and encouraging behaviors, thus promoting highquality LMX relationship. Also, such a relationship make employees feel responsible to pay back their leaders by showing more initiative and enthusiasm in their job as well as proposing constructive suggestions to benefit the organization.

\section{REFERENCES}

[1] J.Y. Duan, "The research of employee voice behavior in China's context: construct, formation mechanism and effect,” Advances in Psychological Science, vol. 19, pp. 185-192, February 2011. "In Chinese"

[2] E.W. Morrison and F.J. Milliken, "Organizational Silence: A Barrier to Change and Development in a Pluralistic World," Academy of Management Review, vol. 25, pp. 706-725, April 2000.

[3] A.J. Elliot and P.G. Devine, "On the motivational nature of cognitive dissonance: Dissonance as psychological discomfort,” Journal of Personality \& Social Psychology, vol. 67,pp. 382-394, March 1994.

[4] Y. Zhu and S.T. Qian, "Analysis and future prospect of the research fronts of inclusive leadership,” Foreign Economies and Management, vol. 36, pp. 55-64, February 2014. "In Chinese”

[5] R.F. Piccolo and J.A. Colquitt, "Transformational Leadership and Job Behaviors: The Mediating Role of Core Job Characteristics,” Academy of Management Journal, vol. 49, pp. 327-340, February 2006.

[6] Y. Lu, Z.L. Peng, and L.N. Yu, "Exploratory research on the influence of leadership style based on grounded theory on employee voice behavior,” Shanghai Management Science, vol. 38, pp. 13-18, April 2016. "In Chinese"

[7] M.D. Mumford, G.M. Scott, B. Gaddis, and J.M. Strange, "Leading creative people: Orchestrating expertise and relationships,” Leadership Quarterly, vol. 13, pp. 705-750, June 2002.

[8] R. Hirak, A.C. Peng, A. Carmeli, and J.M. Schaubroeck, "Linking leader inclusiveness to work unit performance: The importance of psychological safety and learning from failures”, Leadership Quarterly, vol. 23, pp. 107-117, January 2012. 
[9] R. Li, W.Q. Ling, and S.S. Liu, "Influence of superiors' abusive supervision on employee voice behavior and its mechanism," Acta Psychologica Sinica, vol. 41, pp. 1189-1202, December 2009. "In Chinese”
[10] L.D. Jia, Y.X. Chen, J.W. Song, C.P. Li, and J.J. Zhang, "Transformational leadership, organizational trust and commitment of employees: an empirical study of managers in China's context,” Journal of Southeast University (Philosophy and Social Sciences Edition), vol.8, pp. 59-67, June 2006. "In Chinese” 